\title{
Tecnologia Assistiva: entendendo o processo
}

\author{
Fernanda MAIA ${ }^{1}$ \\ Lucy NIEMEYER ${ }^{2}$ \\ Sydney FREITAS ${ }^{3}$
}

RESUMO: O termo "tecnologia assistiva" refere-se a produtos, recursos e serviços especificamente projetados para serem utilizados por pessoas com deficiência ou idosas, com objetivo de prevenir, compensar, ou neutralizar deficiências, limitações na atividade ou restrições na participação, e melhorar a autonomia e a qualidade de vida.

Muito mais do que pelas limitações físicas, as pessoas com deficiência sofrem por limitações sociais. O objetivo principal dos recursos de tecnologia assistiva é proporcionar ao usuário possibilidades para que ele atue no mundo em igualdade de condições com os demais indivíduos.

No ambiente contemporâneo, os produtos desempenham de modo prevalente a função simbólica. Isto não exclui a pessoa com deficiência. Sendo assim, não devemos pensar em produtos que funcionem e permitam que o usuário realize uma atuação, sem considerar os valores que ele dará a esses produtos.

$\mathrm{O}$ designer não desenvolve produtos para normalmente para si próprio e sim para um outro ou grupo específico os quais são diferentes dele. Os valores e significações geradas pelo produto são particulares e compatíveis com a história individual de cada usuário. Somente por meio do entendimento de processos de significações e de sua incorporação nos processos metodológicos no desenvolvimento de recursos de tecnologia assistiva, será possível alcançar produtos adequados a seus usuários finais.

Com base nos dados levantados em entrevistas feitas com terapeutas ocupacionais que produzem objetos de tecnologia assistiva, associados a uma abordagem semiótica, o presente trabalho busca entender parte da relação em que estão envolvidos os sujeitos desse processo de interação mediado por produtos de tecnologia assistiva.

PALAVRAS-CHAVE: Tecnologia assistiva; Design; Semiótica.

\section{Introdução}

O Censo $2000^{4}$ (IBGE) identificou que no Brasil há um expressivo aumento na expectativa de vida, no número de idosos e de pessoas com deficiência. Segundo MONTERO (2007) nos países em desenvolvimento somente 5\%-15\% das pessoas com deficiência têm acesso a instrumentos e tecnologias específicas dos quais necessitam.

\footnotetext{
1 Mestranda do curso de Pós-graduação em Design da Escola Superior de Desenho Industrial ESDI/UERJ. Terapeuta Ocupacional.

${ }^{2}$ Doutora em Comunicação e Semiótica - PUC-RJ; Professora Adjunto ESDI/UERJ;Coordenadora do LABCULT/UERJ;Integrante do LABSEM/UERJ.

${ }^{3}$ Doutor em Engenharia da Produção, linhas de pesquisa:1)Usabilidade, 2)ensino/pesquisa em design, 3)metodologia de pesquisa

${ }^{4}$ Último Censo realizado pelo IBGE.
}

Caderno Seminal Digital Ano 16, nº 13, V. 13 (Jan.- Jun/2010) - ISSN 1806 -9142 
No Brasil poucos são os produtos acessíveis ou especificamente projetados para essa população. A maioria dos produtos utilizados por pessoas com déficits funcionais é importada ou confeccionada por profissionais sem formação específica em atividades projetuais, como é o caso dos terapeutas ocupacionais.

Segundo o site oficial de Tecnologia Assistiva coordenado pela Secretaria de Ciência e Tecnologia para a Inclusão Social (SECIS), do Ministério de Ciência e Tecnologia (MCT), em parceria com o Instituto de Tecnologia Social (ITS Brasil):

Adota-se o conceito de Tecnologia Assistiva (Ajudas Técnicas ou Produtos de Apoio) em sintonia com a ISO 9.999 ou a CIF 2001 da OMS: Qualquer produto, instrumento, estratégia, serviço ou prática, utilizados por pessoas com deficiência e pessoas idosas, especialmente produzidos ou disponíveis no mercado para prevenir, compensar, controlar, aliviar ou neutralizar deficiências, limitações na atividade ou restrições na participação, e melhorar a autonomia e a qualidade de vida. (BRASIL: 2009, P. 01)

No Brasil o termo foi primeiramente citado por Sassaki em 1996. O termo "tecnologia assistiva" é uma tradução aproximada do termo em inglês assistive technology. A palavra assistiva não existe na língua portuguesa, dessa forma as primeiras legislações brasileiras nessa área utilizavam o termo "ajudas técnicas". Em 2007 o Comitê de Ajudas Técnicas (CAT) aprovou Tecnologia Assistiva como nomenclatura oficial.

Alguns estudos internacionais relatam um problema de abandono dos recursos de Tecnologia Assistiva (PHILLIPS e ZHAO, 1993; SCHERER, 2002). No estudo de PHILLIPS e ZHAO (1993) de 1.732 usuários de TA entrevistados, 29,3\% abandonaram o recurso.

No Brasil não existem estudos sobre essa questão específica, porém é possível observarmos empiricamente que essa problemática de abandono dos recursos de tecnologia assistiva também se apresenta. Dessa forma o presente artigo busca entender alguns fatores envolvidos no desenvolvimento de recursos de tecnologia assistiva buscando assim entender fatores que levem a esse abandono.

\section{Levantamento de dados}

No Brasil muitos dos objetos de tecnologia assistiva utilizados pelas pessoas com deficiência são confeccionados por terapeutas ocupacionais, profissional de Caderno Seminal Digital Ano 16, nº 13, V. 13 (Jan.- Jun/2010) - ISSN 1806 -9142 
reabilitação que lida diretamente com o retorno do usuário as suas atividades cotidianas. Tal realidade é reforçada pela escassez desses produtos no mercado.

Buscando entender o processo de desenvolvimento de recursos de tecnologia assistiva utilizado pelos terapeutas ocupacionais foram realizadas entrevistas com 9 profissionais que atuam na produção de tais recursos. O grupo foi formado por profissionais graduados em 6 instituições de ensino diferentes localizadas nos estados do Rio de Janeiro, Pará e Mato Grosso do Sul. Os mesmos tem entre 3 e 29 anos de formados, 4 atuam em instituições públicas, 2 em consultórios particulares e 3 atuam em Instituições públicas e são professores em cursos de graduação de universidades particulares.

Inicialmente foi pedido aos profissionais que classificassem alguns itens em relação a sua importância no processo de desenvolvimento de recursos de tecnologia assistiva. Os entrevistados deveriam dar notas de 0 a 4 sendo: 0, sem importância; 1, pouco importante; 2, regularmente importante; 3, importante e 4, extremamente importante.

A tabela a seguir ilustra o número de entrevistados que classificou cada item de acordo com os níveis de importância:

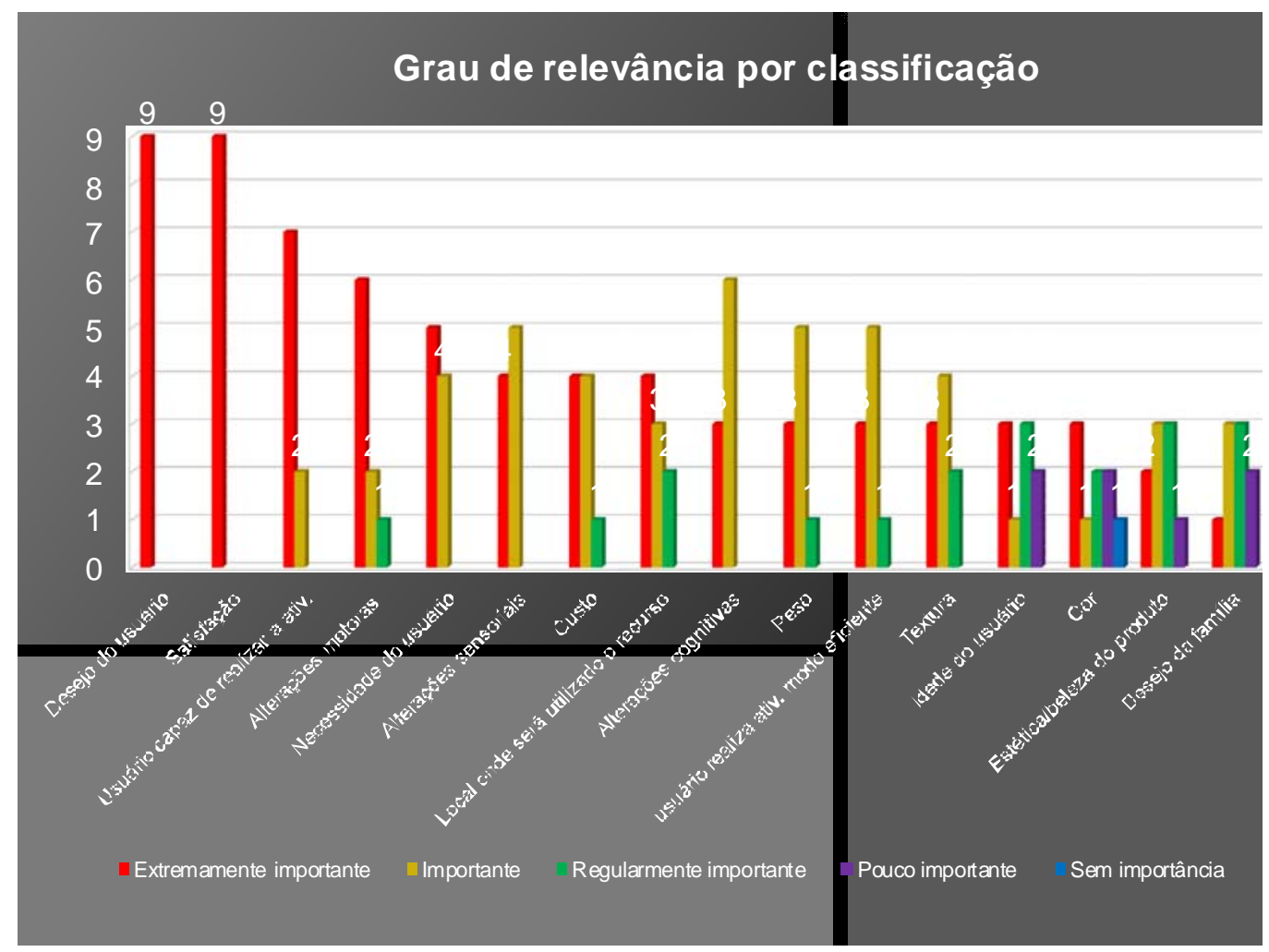

Tabela 1: classificação de importância

Caderno Seminal Digital Ano 16, nº 13, V. 13 (Jan.- Jun/2010) - ISSN 1806 -9142 
Primeiramente observamos que o "desejo do usuário" e a "satisfação com o recurso" são unanimemente considerados de extrema importância. É necessário ressaltar a ligação direta entre esses dois itens. PORTINARI (2008) diferencia o desejo da simples necessidade apresentando-o como uma tendência humana espontânea orientada para um objetivo. DESMET (2002) dentro de seu modelo de geração de emoções relacionadas a produtos inclui o desejo como uma resposta positiva à junção dos objetivos e das tendências motivacionais do indivíduo em relação ao objeto. $\mathrm{O}$ autor coloca as emoções relacionadas a produtos como respostas que serão geradas através da capacidade dos produtos coincidirem ou não com os conceitos e valores do indivíduo. Ambos os autores relacionam o desejo a objetivo e motivação, sendo assim, o usuário só se mostrará realmente satisfeito se os resultados coincidirem com os seus desejos.

Sendo considerados como de menor importância temos os itens "idade do usuário", "cor" e "estética/beleza do produto". Tal contraste demonstra que os terapeutas ocupacionais não entendem esses fatores como relevantes ao desenvolvimento do recurso e sendo assim não associam cor, estética e preferências específicas de cada idade ao conceito de satisfação. CIPINIUK define estética como "uma QUALIDADE ou um valor, para uma só pessoa ou para algumas, tido como objeto de estima ou de DESEJO" (CIPINIUK: 2008, p. 32). O autor ressalta ainda, no trabalho do designer, a necessidade de integrar as faculdades humanas no objeto para que o homem se veja no mundo que ele mesmo criou, pois do contrário o objeto tornase oco de sentido.

A última pergunta da entrevista foi em relação às dificuldades normalmente encontradas. Os problemas citados foram: limitação financeira de recursos disponíveis, dificuldade na modelagem quando o usuário é muito limitado motoramente, dificuldade de aceitação do recurso por parte do usuário e familiares, falta de matéria prima adequada, falta de pessoal capacitado, falta de divulgação do que seja tecnologia assistiva, custo elevado da matéria prima, dificuldade em atender as expectativas do usuário e família, falta de tempo do terapeuta para o processo e ajustes necessários, falta de políticas públicas que auxiliem, dificuldade de acesso as informações relativas a tecnologia assistiva, falta de investimento do governo em tecnologia, dificuldade de comunicação com o usuário e a família, dificuldade quando cuidadores e família não se envolvem, dificuldade de aquisição de alguns materiais importados. 
Muitos dos problemas mencionados pelos entrevistados como dificuldade de aceitação, falta de envolvimento dos familiares e cuidadores e dificuldade em atender as expectativa do usuário e da família, refletem a falta de envolvimento do usuário e dos familiares no decorrer do processo de desenvolvimento do recurso de tecnologia assistiva.

No estudo de PHILLIPS e ZHAO (1993) os autores relatam que quatro fatores foram constatados na pesquisa como os mais significativos em relação ao abandono dos recursos/produtos de tecnologia assistiva: falta de consideração da opinião do usuário no processo, nível de facilidade na aquisição do recurso, desempenho do recurso e mudança nas necessidades e prioridades do usuário. Segundo os autores quando a opinião do usuário é considerada no processo de seleção, existe uma maior tendência a se manter o uso do recurso.

Segundo dados das entrevistas realizadas, os terapeutas ocupacionais consideram o desejo do usuário como muito importante. Mas como eles avaliam esse desejo? O fato de em sua maioria não demonstrarem considerar fatores estéticos e de preferência pessoal como relevantes já demonstra um não entendimento do seu público-alvo.

Muito mais do que limitações físicas, as pessoas com deficiência sofrem por limitações sociais. O objetivo principal dos recursos de tecnologia assistiva é proporcionar ao usuário condições para que ele atue no mundo em igualdade de condições. Porém muitas vezes o próprio produto de tecnologia assistiva torna-se um fator segregador.

Das pessoas com deficiência deve-se esperar que desempenhem seu papel na sociedade e cumpram suas obrigações na qualidade de adultos. A imagem das pessoas com deficiência depende de atitudes sociais baseadas e diferentes fatores que podem constituir a maior barreira à participação e à igualdade. Vê-se a deficiência refletida na bengala branca, nas muletas, nos aparelhos auditivos e nas cadeiras de rodas - mas não a pessoa. É necessário evidenciar a capacidade das pessoas com deficiência e não sua deficiência. (Coordenadoria Nacional para Integração da Pessoa Portadora de Deficiência apud MALLIN: 2004, p.36)

Em um mundo globalizado onde, em sua maioria, os consumidores já possuem muitos dos produtos de que necessitam, o valor intrínseco do objeto torna-se um diferencial. Por que para a pessoa com deficiência seria diferente? Por que devemos 
pensar em produtos que funcionem e permitam que o usuário realize a função, em detrimento do valor que o usuário dará a esse produto?

Norman (2004) sintetiza essa visão de fatores diferenciais do produto ao relatar que na criação de um produto, o designer tem vários fatores a considerar, mas que o que muitas pessoas não entendem é que há também um forte componente emocional em como os produtos são desenvolvidos e colocados para uso. $\mathrm{O}$ autor argumenta que o lado emocional do design pode ser mais crítico para o sucesso de um produto do que seus elementos práticos.

Em um artigo que relata o desenvolvimento de cadeiras de rodas para crianças, DESMET e DIJKHUIS (2003) pontuam a necessidade de um design que considere os aspectos emocionais relativos ao produto e destacam as cadeiras de rodas como bons exemplos de produtos que têm um impacto emocional desagradável. Segundo os autores, por alguma razão o impacto emocional normalmente não é considerado no design de produtos como cadeiras de rodas. Segundo os mesmos, normalmente eles são desenhados baseados em demandas predominantemente relacionadas à ergonomia e tecnologia.

Em seu livro DESMET (2002) baseia-se na premissa de que as emoções são geradas a partir de uma tendência do ser humano de se aproximar de alguma coisa intuitivamente avaliada como positiva (benéfica), e de se distanciar de qualquer coisa intuitivamente avaliada como ruim (nociva). A partir desse pressuposto Desmet propõe um modelo de identificação de emoções relacionadas ao produto onde os conceitos ou valores pré-existentes no sujeito, aliados ao estímulo do objeto, gera um valor positivo, negativo ou neutro que gera um sentimento específico.

Partindo desse modelo Desmet propõe uma ferramenta de avaliação das emoções elicitadas pelo produto (PrEmo) e enfatiza que a emoção só pode ser entendida em relação à pessoa que a experimenta. Dessa forma o design só pode manipular o impacto emocional de um produto a partir do conhecimento dos conceitos da pessoa para a qual o produto é desenvolvido.

\section{A semiótica como ferramenta no entendimento da relação usuário x produto}

A semiótica pode ser entendida como a ciência que estuda os signos. Tudo no mundo a nossa volta tem potencial para ser signo, para representar algo. Dessa forma 
podemos considerar a semiótica como uma ciência que estuda a relação do homem com o mundo a sua volta.

Em seu livro NIEMEYER (2006) utiliza a figura abaixo para explicar a relação objeto - signo - homem:

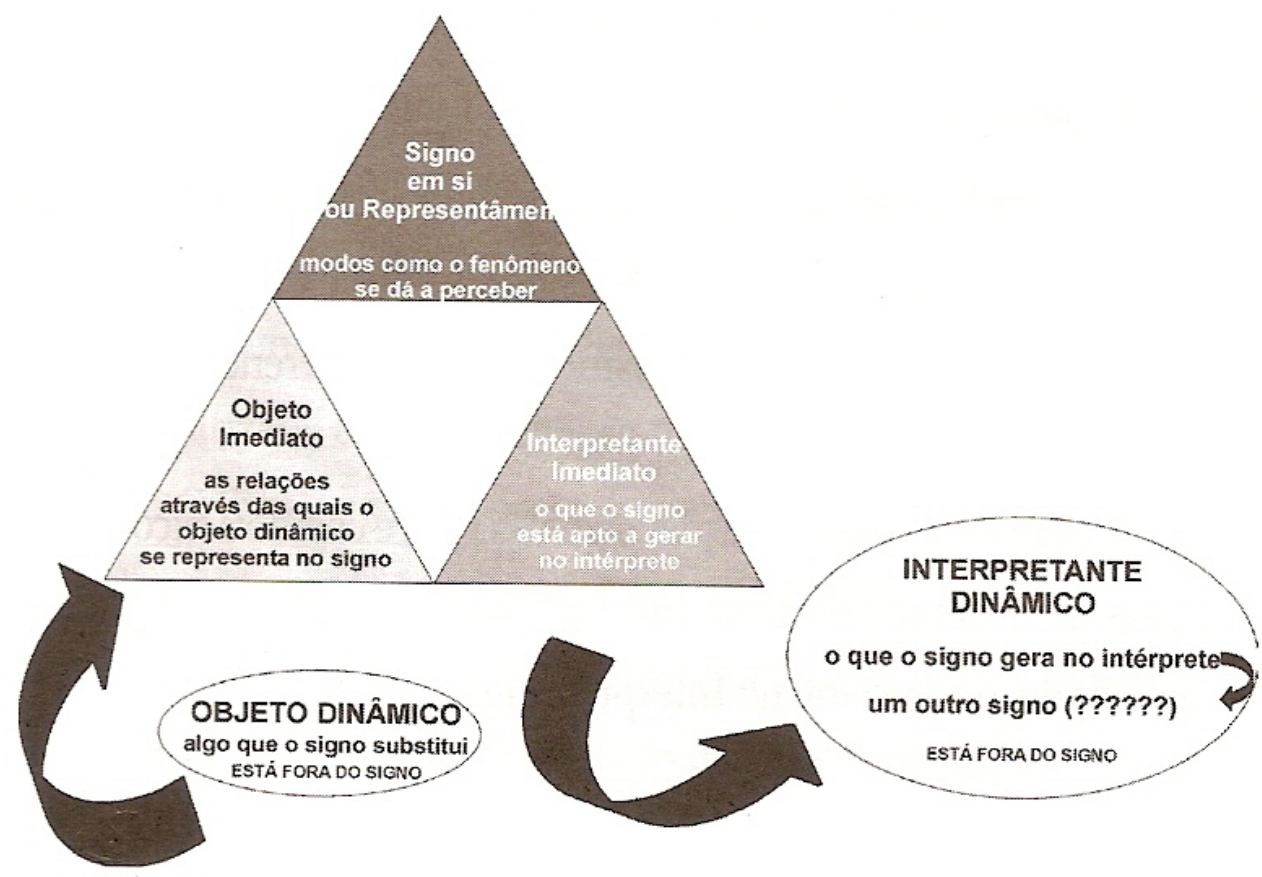

Figura 1 - Objeto dinâmico e interpretante dinâmico

Podemos entender o objeto dinâmico como o objeto em si, algo que o signo substitui. O mesmo é dinâmico porque muitas são as suas facetas que podem ser representadas pelo signo. A faceta específica representada pelo signo é denominada objeto imediato. Santaella (2002) define o objeto imediato como um recorte que o objeto imediato apresenta de seu objeto dinâmico.

O signo tem como seu objetivo o interpretante que é diferente de intérprete. $\mathrm{O}$ intérprete é a pessoa, o indivíduo cuja mente irá participar do processo semiótico. Já o interpretante "é o efeito interpretativo que o signo produz em uma mente real ou meramente potencial" (SANTAELLA: 2002, p. 23). É ele que dará sentido ao signo. O interpretante pode ser dividido em três facetas: interpretante imediato, interpretante dinâmico e interpretante final.

Interpretante imediato está contido no signo. Ele é composto pelas possibilidades geradoras do signo. O interpretante dinâmico será a faceta relacionada ao intérprete específico. O interpretante dinâmico é caracterizado pelas possibilidades de interpretações do próprio intérprete. Tais possibilidades estarão de acordo com o Caderno Seminal Digital Ano 16, nº 13, V. 13 (Jan.- Jun/2010) - ISSN 1806 -9142 
contexto de cada intérprete com o qual o signo entra em contato. O intérprete só poderá gerar um interpretante relacionado ao signo dentro das suas próprias possibilidades. $\mathrm{O}$ interpretante final seria o resultado interpretativo gerado se os interpretantes dinâmicos do signo fossem levados até seu limite. O interpretante final é puramente teórico, pois o interpretante dinâmico está sempre gerando novos signos que irão fazer parte do processo interpretativo. Como afirma Santaella (2002) o interpretante final não pode nunca ser efetivamente alcançado por um intérprete particular. Ele é um limite pensável, mas nunca atingível.

A figura a seguir é um esquema que procura demonstrar a teoria de DESMET (2002), onde o produto (estímulo) associado a conceitos do indivíduo (ponto de referência) será valorizado pelo indivíduo como benéfico, prejudicial ou indiferente, gerando assim emoções específicas a esse processo de valorização/associação.

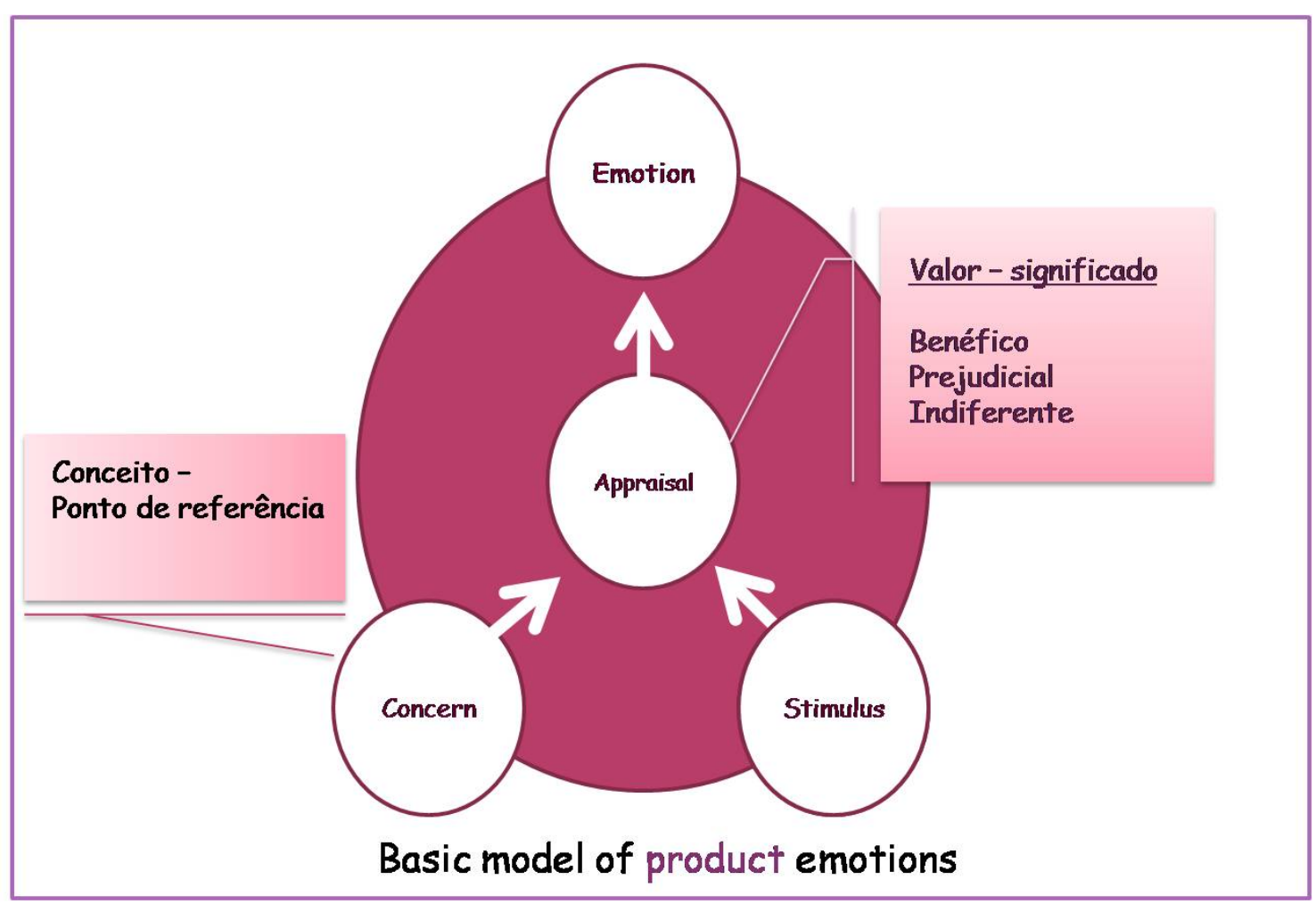

Figura 2: Modelo básico de emoções do produto de Desmet

Partindo de sua teoria verificamos que é necessário que entendamos a relação de significação do usuário em relação ao objeto para gerar as emoções desejadas. NIEMEYER (2006) afirma que nossas respostas emocionais aos produtos são determinadas pelo modo como nós os avaliamos em relação ao nosso conjunto de objetivos, padrões e atitudes. 
Para gerarmos os sentimentos desejados é necessário o entendimento das possibilidades do objeto dinâmico e suas relações com o signo. Cada signo só é capaz de gerar interpretantes dentro das suas possibilidades geradoras.

Da mesma forma Desmet afirma que cada produto terá um potencial de emoções que poderão ser geradas quando associadas a conceitos específicos, próprios de cada indivíduo.

\section{Relação do indivíduo com o objeto de tecnologia assistiva}

Segundo Santaella (2007), Pierce descreve três modalidades de apreensão de todo e qualquer fenômeno. São elas: primeiridade, secundidade e terceiridade.

Ao aplicarmos essas modalidades ao produto de tecnologia assistiva, podemos entender a primeiridade como o primeiro contato do indivíduo com o objeto. È o momento de apreensão, de qualidade, onde existe o sentimento puro e simples sem o entendimento do por que.

A secundidade é o fato material. No caso, é onde o indivíduo passa a ter conhecimento do objeto, sua materialidade, suas funções básicas, suas utilidades e potencialidades.

A terceiridade é a modalidade da lei. Onde se tem o entendimento do funcionamento e regras contidas no produto, onde uma visão técnica do produto está inserida.

Para o usuário muitas vezes o contato do recurso de tecnologia assistiva é um contato de primeiridade. Ele não sabe o que esperar do recurso. Quando o impacto gerado pelo produto não é uma sensação agradável grandes são as chances de recusa ou abandono do recurso. Entender o que o usuário espera e seus valores, torna-se essencial para o sucesso do produto.

Após o contato inicial a relação passa a ser de secundidade. O usuário passa a conhecer o recurso enquanto objeto. Passa a conhecer suas características principais e a definir novos sentimentos em relação ao produto. PAPE et al. (2002) relata que o sentimento de "pertencer à" (fiting in) pode ser mais importante para o usuário de tecnologia assistiva do que independência ou sentimento de controle. Os autores pontuam que a pessoa com deficiência define muitos de seus sentimentos em relação a tecnologia assistiva com base no que acham que os outros vão pensar. 
Se o usuário aceitar o recurso passará a utilizá-lo e com o tempo poderá chegar a uma relação de terceiridade, onde conhecerá o funcionamento do recurso e muitas vezes o relacionará a produtos semelhantes.

No caso do terapeuta ocupacional que pesquisa, prescreve e desenvolve produtos de tecnologia assistiva, a relação é predominantemente de terceiridade, pois ele já conhece os princípios e leis que regem tais recursos.

Se o terapeuta ocupacional, já em um estágio de terceiridade, não conseguir entender as possibilidades geradoras do objeto em um usuário ainda em um estágio de primeiridade, e tentar prever os possíveis impactos e as relações de significações geradas pela relação do indivíduo com os signos gerados pelo objeto, a relação do usuário com esse objeto e o sucesso do recurso poderão estar comprometidos.

\section{Considerações finais}

O design não desenvolve produtos para si e sim para um consumidor específico. Da mesma forma o terapeuta ocupacional não deve desenvolver recursos de tecnologia assistiva levando em consideração o que ele julga ser relevante para o usuário. Os valores e significações geradas pelo produto são específicos e compatíveis com a história individual de cada usuário. Somente através do entendimento desse processo de significações e de sua consideração nos processos metodológicos específicas de desenvolvimento de recursos de tecnologia assistiva, será possível alcançar produtos compatíveis com seus usuários finais.

\section{Lista de tabelas}

Tabela 1- Classificação de importância - pág.02

\section{Lista de figuras}

Figura 1 - Objeto dinâmico e interpretante dinâmico - pág. 05

Figura 2 - Modelo básico de emoções do produto de Desmet - pág. 07 


\section{Referências bibliográficas}

BRASIL. Tecnologia Assistiva. Portal nacional de tecnologia assistiva. Disponível em: http://www.assistiva.org.br. Acesso em: 24 de Março de 2009

CIPINIUK, A. Estética. In: Coelho, L. (org.), Conceitos-chave em design. Pág. 30-34. RJ: Ed. Novas idéias, 2008.

DESMET, P. Designing Emotions. Netherlands, 2002.

DESMET, P. e DIJKHUIS,E. A wheelchair can be fun: a case of emotion-driven design in: Designing pleasurable products and interfaces. Proceedings of the 2003 international conference on designing pleasurable products and interface. PA, USA. 2003. Disponível em: http://portal.acm.org/citation.cfm?id=782903 Acesso em: 16 de Maio de 2009

IBGE. Tendências demográficas no período de 1950/2000. Disponível em: http://www.ibge.gov.br/home/estatistica/populacao/censo2000/tendencias_ demograficas/ comentarios.pdf. Acesso em: 29 Ago. 2008.

MALLIN, V. Uma metodologia de design aplicada ao desenvolvimento de tecnologia assistiva para portadores de paralisia cerebral. PR: UFPR, 2004.

MONTERO, F. Rehabilitation and habilitation: powerfull tools for empowerment. In: International Rehabilitation review. V. 56 n1. Dez. 2007

NIEMEYER, L. Design Atitudinal: uma abordagem projetual. In: Textos selecionados de design. RJ: PPDESDI, PP.97-112. 2006

Elementos de semiótica aplicados ao design. $2^{\mathrm{a}} \mathrm{Ed}$. RJ: 2AB, 2007

NORMAN, D. Emotional design. NY: Basic books, 2004

PAPE, T., KIM, J. e WEINER, B. The shaping of individual meanings assigned to assistive technology: a review of personal factors. Disability and rehabilitation. Vol. 24, n $1 / 2 / 3$, pp 5-20. 2002

PHILLIPS, B. e ZHAO, H. Predictors of assistive technology abandonment. Assistive Technology Journal. V. 5. pp 36-45. 1993

PORTINARI, D. Desejo In: Coelho, L. (org.), Conceitos-chave em design. pp 67-70. RJ: Novas idéias, 2008

SANTAELLA, L. Semiótica aplicada. SP: Ed. Thomson, 2002

O que é semiótica? 26 ed. SP: Ed. Brasiliense, 2007

SCHERER, M. The change in emphasis from people to person: introduction to the special issue on assistive technology. Disability and Rehabilitation, $v 24, n .1 / 2 / 3$, p. 14. 2002. 